University of Wollongong

Research Online

Australian Institute for Innovative Materials -

Papers

Australian Institute for Innovative Materials

$1-1-2014$

\title{
Liquid ink deposition from an atomic force microscope tip: deposition monitoring and control of feature size
}

\author{
Cathal D. O'Connell \\ University of Wollongong, coc531@uowmail.edu.au \\ Michael J. Higgins \\ University of Wollongong, mhiggins@uow.edu.au \\ David Marusic \\ Univeristy of Wollongong \\ Simon E. Moulton \\ University of Wollongong, smoulton@uow.edu.au \\ Gordon G. Wallace \\ University of Wollongong, gwallace@uow.edu.au
}

Follow this and additional works at: https://ro.uow.edu.au/aiimpapers

Part of the Engineering Commons, and the Physical Sciences and Mathematics Commons 


\title{
Liquid ink deposition from an atomic force microscope tip: deposition monitoring and control of feature size
}

\begin{abstract}
The controlled deposition of attoliter volumes of liquid inks may engender novel applications such as targeted drug delivery to single cells and localized delivery of chemical reagents at nanoscale dimensions. Although the deposition of small organic molecules from an atomic force microscope tip, known as dip-pen nanolithography (DPN), has been extensively studied, the deposition of liquid inks is little understood. In this work, we have used a set of model ink-substrate systems to develop an understanding of the deposition of viscous liquids using an unmodified AFM tip. First, the growth of dot size with increasing dwell time is characterized. The dynamics of deposition are found to vary for different ink-substrate systems, and the change in deposition rate over the course of an experiment limits our ability to quantify the ink-transfer dynamics in terms of liquid properties and substrate wettability. We find that the most critical parameter affecting the deposition rate is the volume of ink on the cantilever, an effect resulting in a 10 -fold decrease in deposition rate $(\mathrm{aL} / \mathrm{s})$ over $2 \mathrm{~h}$ of printing time. We suggest that a driving force for deposition arises from the gradient in Laplace pressure set up when the tip touches the substrate. Second, the forces acting upon the AFM cantilever during ink deposition were measured in order to gain insight into the underlying ink-transfer mechanism. The force curve data and simple geometrical arguments were used to elucidate the shape of the ink meniscus at the instant of deposition, a methodology that may be used as an accurate and real-time means of monitoring the volume of deposited dots. Taken together, our results illustrate that liquid deposition involves a very different transfer mechanism than traditionally ascribed to DPN molecular transport.
\end{abstract}

\section{Keywords}

ink, deposition, atomic, force, microscope, tip, monitoring, control, liquid, feature, size

Disciplines

Engineering | Physical Sciences and Mathematics

\section{Publication Details}

O'Connell, C. D., Higgins, M. J., Marusic, D., Moulton, S. E. \& Wallace, G. G. (2014). Liquid ink deposition from an atomic force microscope tip: deposition monitoring and control of feature size. Langmuir: the ACS journal of surfaces and colloids, 30 (10), 2712-2721. 


\section{Liquid ink deposition from an atomic force}

\section{microscope tip: deposition monitoring and control of \\ feature size}

Cathal D. O'Connell, Michael J. Higgins, David Marusic, Simon E. Moulton, Gordon G.

$$
\text { Wallace* }
$$

ARC Centre of Excellence for Electromaterials Science, Intelligent Polymer Research Institute, AIIM Facility, Innovation Campus, University of Wollongong, Wollongong, NSW 2522,

Australia 


\section{ABSTRACT.}

The controlled deposition of attolitre volumes of liquid inks may engender novel applications such as targeted drug delivery to single cells and localized delivery of chemical reagents at nanoscale dimensions. Although the deposition of small organic molecules from an atomic force microscope tip, known as dip-pen nanolithography (DPN), has been extensively studied, the deposition of liquid inks is little understood. In this work we have used a set of model inksubstrate systems to develop an understanding of the deposition of viscous liquids using an unmodified AFM tip. Firstly, the growth of dot-size with increasing dwell-time is characterized. The dynamics of deposition are found vary for different ink-substrate systems and the change in deposition rate over the course of an experiment limits our ability to quantify the ink-transfer dynamics in terms of liquid properties and substrate wettability. We find that the most critical parameter affecting deposition rate is the volume of ink on the cantilever, an effect resulting in a ten-fold decrease in deposition rate $(\mathrm{aL} / \mathrm{s})$ over two hours printing time. We suggest that a driving force for deposition arises from the gradient in Laplace pressure set up when the tip touches the substrate. Secondly, the forces acting upon the AFM cantilever during ink deposition were measured in order to gain insight into the underlying ink-transfer mechanism. The force curve data and simple geometrical arguments were used to elucidate the shape of the ink meniscus at the instant of deposition, a methodology which may be used as an accurate and realtime means of monitoring the volume of deposited dots. Taken together, our results illustrate that liquid deposition involves a very different transfer mechanism than traditionally ascribed to DPN molecular transport. 


\section{INTRODUCTION}

Dip-pen nanolithography (DPN) is a nanofabrication technique which uses an atomic force microscope (AFM) tip to direct-write functional materials at sub $50 \mathrm{~nm}$ resolution. ${ }^{1}$ The deposition of alkanethiol molecules onto a gold substrate by DPN has been studied extensively over the past decade. ${ }^{2-11}$ In molecular ink DPN, control of feature-size, and therefore pattern fidelity, arises from an empirical understanding of the rate of deposition over a range of 'dwell times' for dot printing or 'write-speeds' for line writing. ${ }^{2,3}$ Deposition rate is influenced by a multitude of critical parameters including ink loading, ${ }^{4}$ tip sharpness, ${ }^{5}$ relative humidity, ${ }^{3}$ temperature, ${ }^{6}$ surface roughness, ${ }^{7}$ molecular diffusivity and dissolution kinetics ${ }^{8}$ and others. The mechanism of molecular transport has been given a theoretical framework ${ }^{9}$ and progress in refining the technique has become a lively conversation involving the interplay of experiment, ${ }^{4}$ theory, ${ }^{8,12}$ and numerical simulation. ${ }^{7,10,11}$ Recently, the DPN technique has been applied to the deposition of liquid inks. ${ }^{13-19}$ Liquid inks are attractive due to their versatility in depositing on various materials. ${ }^{17,20}$ They can also be used to generate $3 \mathrm{D}$ structures not achievable by molecular inks, such as spherical cap lenses for sub-wavelength optical lithography ${ }^{18}$ or for the molded fabrication of stamps. ${ }^{19}$ Liquid inks have also been exploited as universal 'ink-carriers' for functional materials or biological molecules ${ }^{15}$ and hydrogels loaded with proteins have been patterned for a novel drug-delivery approach targeting single cells. ${ }^{21}$ Confidence in any fabrication technique is built upon its ability to faithfully reproduce the user's design. The stringent control of feature size, however, is challenging in AFM deposition of liquid inks. For example, it is necessary to 'bleed' the pen of excess ink before reproducible deposition is obtained. ${ }^{13,14,17}$ Even after bleeding, the coefficient of variation in dot diameter is often quoted at 
between $10-15 \% .^{22,23}$ A $10 \%$ variation in diameter would correspond to a $21 \%$ variation in feature area, and a 33\% variation in feature volume (from spherical cap geometry).

The explanation for such printing inconsistency is made difficult because, as opposed to molecular ink DPN, a solid framework of understanding does not presently exist for deposition of liquid inks from an AFM tip. In particular, although the driving force for deposition has been described as arising from 'physioadsorption' or 'capillarity', ${ }^{13,14}$ this mechanism has not been quantitatively treated. The relative effects of ink properties such as viscosity and surface tension are also poorly understood. A model describing the rate of flow of ink onto the substrate (dwelltime dependence) has not been presented. When discussing liquid ink deposition, the language ('diffusion coefficient') and the analysis procedures for molecular ink DPN are sometimes used, despite the patently different morphologies of resulting features (i.e. spherical caps as opposed to two-dimensional circles). ${ }^{15,16}$

Although explicit studies of liquid deposition from an unmodified AFM tip are lacking, some groups have studied the related system of liquid deposition from a nano-fountain probe (or liquid nanodispenser). ${ }^{24-31} \mathrm{~A}$ nano-fountain probe is an AFM tip with a nanofluidic channel (typically with diameter $<100 \mathrm{~nm}$ ) emerging at the tip apex and through which liquid can be dispensed. The key parameters in nano-fountain probe deposition were found to be the aperture diameter as well as tip and substrate hydrophobicity. ${ }^{24,26,27}$ Despite some promising demonstrations of attolitre volume dispensing, this technique has not been widely adopted, possibly due to issues with blockage of the nano-channels. Other groups have also studied the capillary forces between an AFM tip coated in liquid and a surface. ${ }^{32,33}$ This system is highly pertinent to many fields as the nanoscale tip provides a 'model asperity' for studying the fundamental origins of adhesion, wear and lubrication. ${ }^{34,35}$ 
In this article we use model ink-substrate systems (exhibiting differing viscosities and wettabilities) to gain understanding of the ink transfer process in AFM deposition of liquid inks. This work provides new insight in two main areas: (1) By studying the dwell-time/dot-size relationship of various ink-substrate systems we find that, although dots with volume ranging 5 orders of magnitude (0.1-5000 aL) can be deposited, the deposition rate decreases dramatically over the course of an experiment. We find that the volume of ink on the pen is the dominant factor affecting deposition rate. This has the practical consequence that the size of printed droplets cannot be predefined using dwell time. (2) One way to circumvent this change in deposition rate, may be to monitor deposition in situ and calibrate on the fly. By measuring the forces on the AFM cantilever during ink deposition we elucidate the shape of the meniscus at the instant of deposition. We illustrate that this method can be used to monitor the size of invididual droplets in real time.

\section{EXPERIMENTAL SECTION}

Materials. Octadecyltrimethoxysilane was obtained from Sigma Aldrich. Norland Optical Adhesives are highly viscous, UV curable, acrylic based liquid adhesives. The formulations NOA 68 and NOA 68T were obtained from Norland Products (Cranbury NJ, USA). A summary of the composition of each adhesive is included in Table 1. 
Table 1: The composition of each NOA ink.

\begin{tabular}{c|cc}
\hline & $\begin{array}{c}\text { Norland Optical } \\
\text { Adhesive 68 } \\
\text { (NOA 68) }\end{array}$ & $\begin{array}{c}\text { Norland Optical } \\
\text { Adhesive 68T } \\
\text { (NOA 68T) }\end{array}$ \\
\hline Mercapto-ester & $45-65 \%$ & $45-65 \%$ \\
Tetrahydrofurfuryl Methacrylate & $5-20 \%$ & $5-20 \%$
\end{tabular}

Liquid properties. Viscosity measurements were performed on a (shear-controlled) AR-G2 Rheometer (TA Instruments) using a cone and plate geometry at $22^{\circ} \mathrm{C}, 25^{\circ} \mathrm{C}$ and $30^{\circ} \mathrm{C}$. The values quoted throughout the test were for $22^{\circ} \mathrm{C}$. Surface tension measurements were made using the pendant drop technique on a OCA Contact Angle System (Dataphysics) at $22{ }^{\circ} \mathrm{C}$. Contact angles were measured using the sessile drop method. In the case of highly viscous liquids the contact angle was measured as a function of time after deposition, and final results determined after a 24 hour equilibration period. Measurements repeated on the same drops 48 hours and several days later indicated no further change in drop morphology. The goniometer set-up consists of a horizontal microscope focused on the drop of interest which is illuminated by a diffuse-back light for increased contrast. A snap-shot of the drop is taken and the drop-shape is fit by the software to the Young-Laplace equation.

Substrate preparation. $\mathrm{Si} / \mathrm{SiOx}$ wafers were pretreated with a generic cleaning protocol consisting of bath sonication while immersed in various solvents (acetone, isopropanol, water). This was followed by a hot piranha treatment (immersion in a freshly prepared 1:3 ratio $\mathrm{H}_{2} \mathrm{O}_{2}: \mathrm{H}_{2} \mathrm{SO}_{4}$ mixture for 30 minutes at $80{ }^{\circ} \mathrm{C}$ ) and final rinsing with copious deionized water (Milli-Q). Hydrophilic substrates were prepared by plasma treatment of a clean $\mathrm{Si} / \mathrm{SiOx}$ wafer (Harrick Plasma Cleaner, $\mathrm{O}_{2}$ or air plasma at 1100 mTorr, 10 mins) immediately prior to DPN printing. Hydrophilicity of the substrate was confirmed by water contact angle $\left(\sim 0^{\circ}\right)$. 
Hydrophobic substrates were prepared by functionalization of the $\mathrm{Si} / \mathrm{SiOx}$ substrate with octadecyltrimethoxysilane (ODTMS). Briefly; after pretreatment the substrates were plasma treated (as above), then immersed in a freshly prepared solution of $0.1 \%$ ODTMS in isopropanol for 5 minutes, before a further 5 minutes on a hotplate $\left(80^{\circ} \mathrm{C}\right)$ for 5 minutes. The substrates were dipped in the $0.1 \%$ ODTMS/isopropanol solution and placed on the hotplate $\left(80^{\circ} \mathrm{C}, 5\right.$ minutes) a further three times to ensure consistent levels of silanization. Hydrophobicity of the substrate was confirmed by water contact angle $\left(\sim 88^{\circ}\right)$. This degree of hydrophobicity was maintained for several weeks as confirmed by repeated water contact angle measurements.

AFM deposition protocol. AFM deposition experiments were performed using an Nscriptor system (NanoInk, Skokie, IL) in an environment controlled at $45 \%$ relative humidity and $22^{\circ} \mathrm{C}$ temperature. The NOA ink of interest was wetted onto a single probe on an array of NanoInk MType probes (NanoInk part \# PEN-0300-03, material Si3N4, length $107 \mu \mathrm{m}$, width $22 \mu \mathrm{m}$, spring constant $0.5 \mathrm{~N} / \mathrm{m}$ ) by dipping into the filled microwell of a NanoInk Universal Inkwell (part \# IWL-0009-03). The tip was bled of excess ink in a method similar to that previously reported for AFM deposition of liquid inks by bringing it in contact with the substrate in several (typically 45) locations, until deposition of large $\sim 10 \mu \mathrm{m}$ 'bleed-spots' ceased. ${ }^{14,36}$ Patterns were generated using the InkCAD software (v 2.7.1) provided with the Nscriptor system.

AFM measurements. AFM force curve measurements were performed in air on an Asylum MFP-3D system (Asylum Research, Santa Barbara, CA). Resonance frequencies of all cantilevers were measured using the thermal noise method. The stiffness and sensitivity of each cantilever was measured prior to dipping in ink. Force maps were processed using Asylum Research software (based in the Igor-Pro environment, Wavemetrics). The raw data of cantilever deflection voltage versus z-piezo extension was converted to force vs tip-sample separation using 
the measured stiffness and sensitivity of the cantilever. In addition to block-processed force maps to calculated maximum adhesion, force curve analysis was performed manually for each force curve to extract extension length data. Topographical images were generated on the Asylum MFP-3D instrument in intermittent contact mode. Morphologies of the printed features were analyzed using the Particle Size plug-in for the Asylum Research software.

\section{RESULTS AND DISCUSSION}

\subsection{Liquid properties}

The UV curable acrylic based liquid inks were chosen as they contain minimal volatile components and so their liquid properties remain stable over many hours. Deposited droplets could be imaged by AFM in A/C mode and were found not to change in volume or morphology over several weeks. A summary of the liquid properties for each ink is presented in Table 1. In particular, the inks are highly viscous, with viscosities of 5.49 Pa.s for the NOA68 ink and 24.86 Pa.s for the NOA68T ink.

Table 2. Liquid properties of all NOA inks and of water.

\begin{tabular}{|c|c|c|c|c|c|}
\hline & \multirow{2}{*}{$\begin{array}{c}\text { Density } \\
\qquad \begin{array}{c}\rho \\
(\mathrm{g} / \mathrm{ml})\end{array}\end{array}$} & \multirow{2}{*}{$\begin{array}{c}\text { Viscosity } \\
\left(22^{\circ} \mathrm{C}\right) \\
\mu \\
(\text { Pa.s })\end{array}$} & \multirow{2}{*}{$\begin{array}{c}\text { Surface tension } \\
\sigma \\
(\mathrm{mN} / \mathrm{m})\end{array}$} & \multicolumn{2}{|c|}{$\begin{array}{l}\text { Static Contact Angles } \\
\text { (macroscopic) }\end{array}$} \\
\hline & & & & $\begin{array}{c}\text { Si (-OH) } \\
\left({ }^{\circ}\right)\end{array}$ & $\begin{array}{c}\mathrm{Si}\left(-\mathrm{CH}_{3}\right) \\
\left({ }^{\circ}\right)\end{array}$ \\
\hline Water & 0.998 & 0.001 & 72.7 & $\sim 0$ & $\begin{array}{l}87.8 \\
(5.5)\end{array}$ \\
\hline NOA 68 & $\begin{array}{c}1.136 \\
(0.001)\end{array}$ & $\begin{array}{c}5.49 \\
(0.13)\end{array}$ & $\begin{array}{c}34.2 \\
(0.04)\end{array}$ & $\begin{array}{c}4.5 \\
(0.5)\end{array}$ & $\begin{array}{l}37.0 \\
(4.2)\end{array}$ \\
\hline NOA $68 T$ & $\begin{array}{l}1.156 \\
(0.001)\end{array}$ & $\begin{array}{l}24.86 \\
(0.56)\end{array}$ & $\begin{array}{l}26.7 \\
(0.5)\end{array}$ & $\begin{array}{l}6.6 \\
(0.4)\end{array}$ & $\begin{array}{l}38.2 \\
(3.6)\end{array}$ \\
\hline
\end{tabular}

*Values in parentheses indicate the standard deviation over multiple samples $(\mathrm{n}=2$ for density measurements; $\mathrm{n}=3$ for viscosity measurements; $\mathrm{n}=6$ or greater for surface tension measurements; $n=8$ or greater for contact angle measurements). 


\subsection{Dwell time dependence}

The growth of feature-size with dwell-time is a critical parameter in DPN of molecules as it enables feature generation from sub $50 \mathrm{~nm}$ up to $\sim 10 \mu \mathrm{m}$ length scale. Investigations of the 'transport rate' relationship have been the basis for many studies into molecular ink transfer mechanisms. ${ }^{3,4,37,38}$ However, dedicated studies using liquid inks are lacking.

We have systematically investigated the dwell time dependence of dot-size for each NOA ink on both hydrophilic (plasma cleaned) and hydrophobic (ODTMS functionalised) silicon substrates. Varying deposition dynamics were observed for different ink-substrate systems. However, we found that the factor affecting transport rate most dramatically is not any intrinsic liquid or interfacial property; rather, it is the volume of ink on the cantilever at the time of printing.

\subsubsection{Growth of dot radius with dwell time}

Figure 1 shows the dependence of dot-radius on dwell time for each ink-substrate system. Figure $1 \mathrm{~A}$ and $1 \mathrm{~B}$ show dot radius (as measured by AFM) plotted against dwell time for the NOA68 (5.5 Pa.s) ink and the NOA68T (24.9 Pa.s) ink on hydrophilic $\mathrm{Si} / \mathrm{SiO}_{2}$ respectively. Figure 1C and 1D show dot radius plotted against dwell time for the NOA68 ink and the NOA68T ink on hydrophobic (alkane functionalised) $\mathrm{Si} / \mathrm{SiO}_{2}$ respectively. In each plot, data from two calibration-grids are shown, both obtained during the same experiment, under the same environmental conditions, by the same pen. The 'early' grids were printed soon after inking the pen and the 'late' grids were printed after two hours printing time, when much of the ink on the pen had been expended.

Different ink-substrate systems followed different deposition dynamics. The NOA68 ink

exhibited a power-law $\left(r \sim \mathrm{t}^{1 / 2}\right)$ dependence of dot radius on dwell time (Figure $\left.1 \mathrm{~A}\right)$. A similar $\mathrm{t}^{1 / 2}$ 
dependence is often observed in microfluidics, for example in the Lucas-Washburn equation for filling of micro-channels. In the case of microfluidic channels, the $x \sim t^{1 / 2}$ filling rate arises from a situation of constant filling pressure acting over an increasing channel length (therefore increasing hydraulic resistance) ${ }^{39,40}$ However, the $r \sim \mathrm{t}^{1 / 2}$ behavior was not general. The NOA68T ink on the shows a linear $(r \sim t)$ growth of radius with dwell time on the hydrophilic substrate (Figure 1 B). On the hydrophobic substrate, both the NOA68 and the NOA68T inks exhibit two step deposition kinetics where feature radius at short dwell times $(0.02-0.25 \mathrm{~s})$ grows faster than at longer dwell times $(0.5-5 \mathrm{~s})$ (Figure $1 \mathrm{C}$ and $\mathrm{D})$. This two-step dynamics may arise from capillary induced spreading at short dwell times (nanoscale features), which is then limited by the rate of flow down the tip at longer dwell times.

The varying deposition kinetics highlights the difficulty in using empirical dwell time relationships to control feature size. Though we do not attempt rigorous explanations of the differing deposition mechanisms, a summary of the observed dwell-time behavior, as well as the deposition rates (obtained from fitted trendlines) is provided in Table 3.

In all systems, we observed a significant decrease in the rate of deposition for the late grid, compared with the early grid. This suggests a general influence of the volume of ink on the cantilever on the deposition rate. This aspect is discussed in detail in Section 3.2.2 below. 

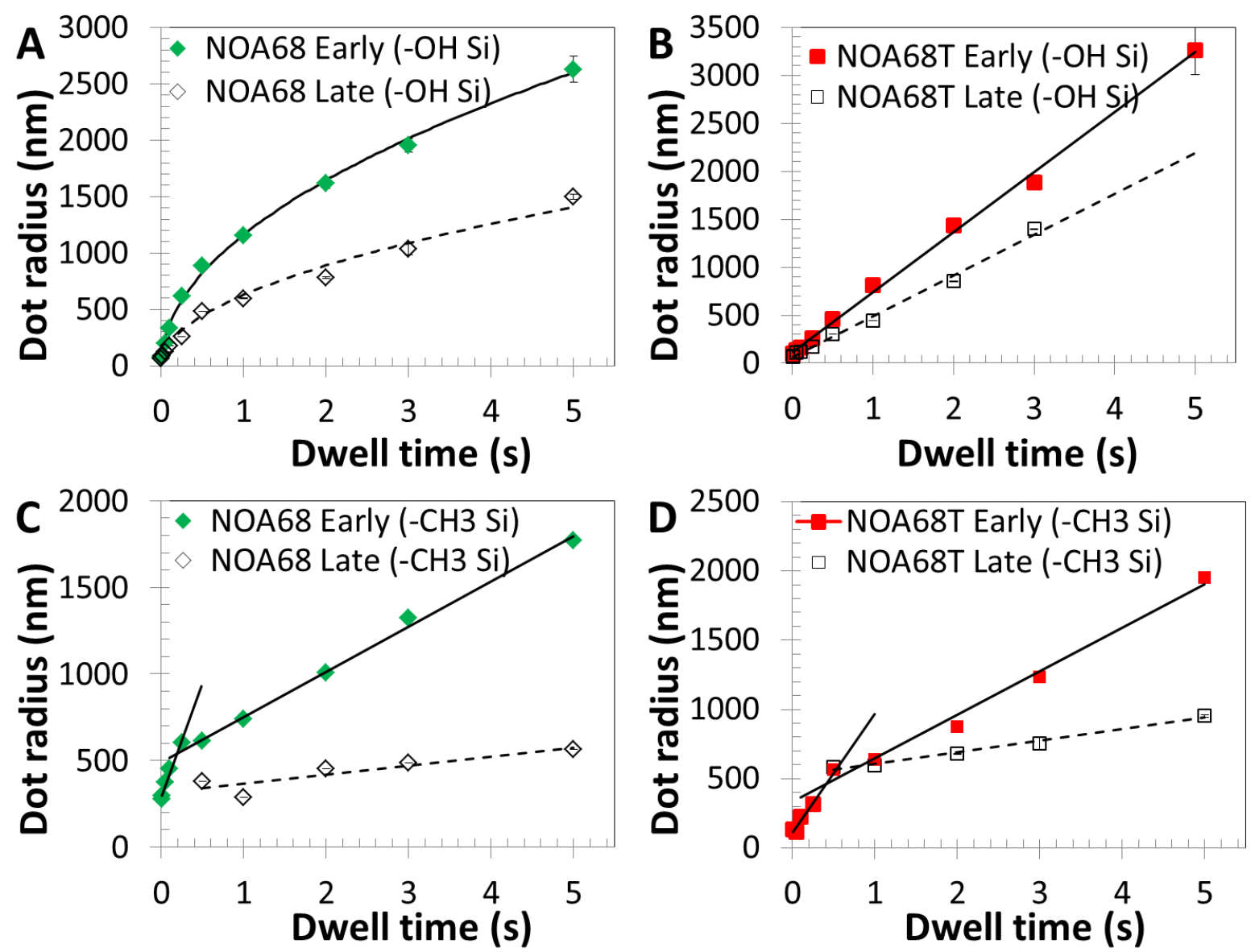

Figure 1: (A) Dot radius (as measured by AFM) versus dwell time for the NOA68 (5000 mPa.s) ink on hydrophilic Si. The 'early' grid (filled green diamonds) was printed soon after inking the pen and the 'late' grid was printed when much of the ink on the pen had been expended. The deposition rate of the second grid is markedly different from that of the early grid due to a decreased volume of ink on the cantilever. The solid black and dashed black lines are fitted trendlines. A summary of the fitting parameters for the trendlines is shown in Table 3. (B) A similar dot-radius versus dwell time plot for the NOA68T (24.9 Pa.s) on the hydrophilic $\mathrm{Si}^{-\mathrm{SiO}_{2}}$. (C) Dot-radius versus dwell time for the NOA68 ink on the hydrophobic (alkane terminated) $\mathrm{Si} / \mathrm{SiO}_{2}$. (D) Dot-radius versus dwell time for the NOA68T ink on the hydrophobic (alkane terminated) $\mathrm{Si} / \mathrm{SiO}_{2}$. 
Table 3: Varying deposition dynamics for different ink-substrate systems

\begin{tabular}{|c|c|c|c|c|c|c|}
\hline \multirow{2}{*}{ Ink } & \multirow{2}{*}{ Substrate } & \multirow{2}{*}{$\begin{array}{c}\text { Deposition } \\
\text { dynamics }\end{array}$} & \multicolumn{2}{|c|}{ Deposition rate* } & \multicolumn{2}{|c|}{ Min dot radius (nm) } \\
\hline & & & Early & Late & Early & Late \\
\hline NOA 68 & $\mathrm{Si} / \mathrm{SiO}_{2} / \mathrm{OH}$ & $r \sim t^{1 / 2}$ & $\begin{array}{c}1164 \mathrm{~nm} / \mathrm{s}^{1 / 2} \\
(0.998)\end{array}$ & $\begin{array}{c}629 \mathrm{~nm} / \mathrm{s}^{1 / 2} \\
(0.985)\end{array}$ & 81 & 63 \\
\hline NOA 68T & $\mathrm{Si} / \mathrm{SiO}_{2} / \mathrm{OH}$ & $r \sim t$ & $\begin{array}{c}625 \mathrm{~nm} / \mathrm{s} \\
(0.997)\end{array}$ & $\begin{array}{c}426 \mathrm{~nm} / \mathrm{s} \\
(0.993)\end{array}$ & 73 & 63 \\
\hline NOA 68 & $\mathrm{Si} / \mathrm{SiO}_{2} / \mathrm{CH}_{3}$ & Two-step & 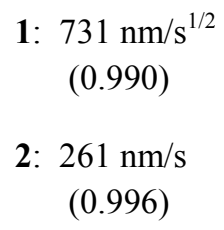 & $\begin{array}{l}\text { 1: } \mathrm{N} / \mathrm{D} \\
\text { 2: } 52 \mathrm{~nm} / \mathrm{s} \\
(0.79)\end{array}$ & 279 & 289 \\
\hline NOA $68 T$ & $\mathrm{Si} / \mathrm{SiO}_{2} / \mathrm{CH}_{3}$ & Two-step & 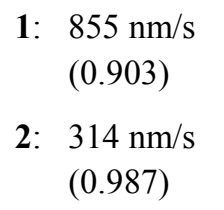 & $\begin{array}{ll}\text { 1: } & \mathrm{N} / \mathrm{D} \\
\text { 2: } & 84 \mathrm{~nm} / \mathrm{s} \\
& (0.990)\end{array}$ & 114 & 215 \\
\hline
\end{tabular}

* Values in parenthesis indicate $R^{2}$ value of linear fit.

\subsubsection{Growth of dot volume with dwell time}

Control of feature-size for liquids is made more problematic by the 3 dimensional nature of the resulting features; small changes in radius can result in comparatively large increases in volume ( $V_{d o t} \sim r^{3}$ for a spherical cap). The control of deposition volume is crucial for many applications, for example those which involve monitoring of local fluorescence, ${ }^{15}$ drug delivery targeting single cells, ${ }^{21}$ or applications involving the fabrication or repair of electrical components. ${ }^{14}$

Dwell time could be used to deposit feature-sizes ranging four orders of magnitude, typically from less than 0.1 aL (at $0.002 \mathrm{~s}$ dwell time) to over 1000 aL (at $5 \mathrm{~s}$ dwell). Figure 2 shows the dot-volume/dwell-time relationship for all four ink-substrate systems. Figure 2A shows a 2D rendered AFM topography image of a typical dwell time calibration grid illustrating increasing dot size with dwell time. Figures $2 \mathrm{~B}$ and $2 \mathrm{C}$ show dot volume (as measured by AFM) plotted 
against dwell time for the NOA68 (5.5 Pa.s) ink and the NOA68T (24.9 Pa.s) ink on hydrophilic $\mathrm{Si} / \mathrm{SiO}_{2}$ respectively. Figures $2 \mathrm{D}$ and $2 \mathrm{E}$ show dot volume plotted against dwell time for the NOA68 ink and the NOA68T ink on hydrophobic (alkane functionalised) $\mathrm{Si} / \mathrm{SiO}_{2}$ respectively. Figures $2 \mathrm{~F}-\mathrm{H}$ show optical micrographs of an M-type probe prior to inking (figure $2 \mathrm{~F}$ ), just after filling with ink (figure 1G), and the same probe after printing for 2 hours and much of the ink has been depleted (figure 1H).

Over the course of an experiment, there is a dramatic decrease in deposition rate for each ink on both the hydrophilic and hydrophobic substrates. Considering first Figure 2B. Data for two grids are shown, both printed during the same experiment, under the same environmental conditions, by the same pen. The 'early' grid (filled green diamonds with solid line) was printed soon after inking the pen and the 'late' grid (open black diamonds with dashed line) was printed when much of the ink on the pen had been expended. For identical dwell times, the early grid clearly deposits much larger features than the late grid. For example, at a dwell time of $5 \mathrm{~s}$ the early grid yields an average dot volume of $1700 \mathrm{aL}$, whereas the late grid yields a dot volume of $180 \mathrm{aL}$. A similar order of magnitude difference in feature size between early and late grids is observed for all dwell times. The inset is a magnified view of the shortest dwell time features, illustrating the generality of the divergence. Similar behaviour is observed for the NOA68T (24.9 Pa.s) ink on the hydrophilic substrate (Figure 2 C). Despite the varying deposition rates displayed for early and late grids, it is interesting to note that the minimum feature sizes remain similar in each case.

On the hydrophobic substrate, the deposition rates for late grids are again much decreased for both inks. For the NOA68 ink (Figure $2 \mathrm{D}$ ), at a dwell time of $5 \mathrm{~s}$ the early grid yields an average dot volume of $3200 \mathrm{aL}$, whereas the late grid yields a dot volume of $64 \mathrm{aL}$. As shown in the 
inset, though dots were deposited for short dwell times in the early grid, none were observed for the late grid. Similar behaviour is observed for the NOA68T ink on the hydrophobic substrate (Figure 2 E).
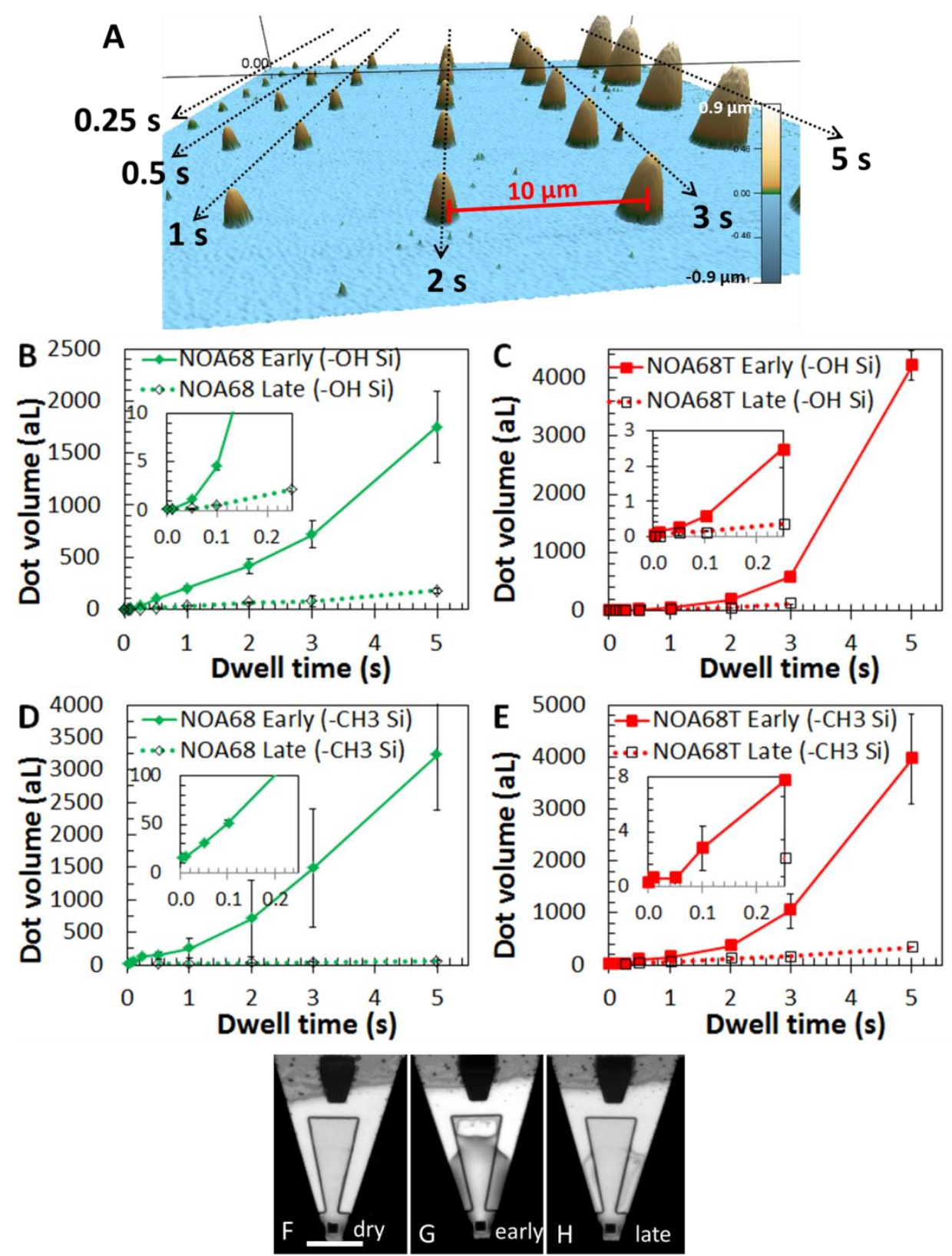

Figure 2. Controlling dot-size using the dwell time parameter: (A) 3D rendered AFM topography image of a typical dwell time calibration grid illustrating increasing dot size with dwell time, scale bar $10 \mu \mathrm{m}$; (B) Dot volume (as measured by AFM) versus dwell time 
for the NOA68 (5000 mPa.s) ink on hydrophilic $\mathrm{Si}_{/} \mathrm{SiO}_{2}$. The inset is a magnified view of the shortest dwell time features. (C) A similar dot-volume versus dwell time plot for the NOA68T (24.9 Pa.s) on the hydrophilic $\mathrm{Si} / \mathrm{SiO}_{2}$. (D) Dot-volume versus dwell time for the NOA68 ink on the hydrophobic (alkane terminated) $\mathrm{Si}_{/} / \mathrm{SiO}_{2}$. (E) Dot-volume versus dwell time for the NOA68T ink on the hydrophobic (alkane terminated) $\mathrm{Si} / \mathrm{SiO}_{2}$. (F) Optical micrograph of a dry M-type probe (as used in this study) prior to inking, scale bar $10 \mu \mathrm{m}$. (G) Optical micrograph of an M-type probe just after filling with NOA68T ink. The deposition rate of this filled pen corresponds with the 'early grid above. (H) Optical micrograph of the same probe after printing for 2 hours and much of the ink has been depleted.

We suggest that this change in deposition rate may arise due to a decreased Laplace pressure gradient, arising due to the depletion of ink volume on the cantilever. According to the YoungLaplace equation, the constricting force of surface tension on a droplet-air interface results in an increased pressure inside a liquid droplet relative to outside. In general, the pressure difference $\left(\triangle P_{\text {Lap }}\right.$, known as the Laplace pressure or overpressure) is a product of the liquid surface tension $(\gamma)$ and the mean curvature of the interface $(\kappa)$ :

$$
\Delta P_{\text {Lap }}=\gamma \kappa
$$

The mean curvature is given by $\kappa=\left(\frac{1}{\mathrm{R}_{1}}+\frac{1}{\mathrm{R}_{2}}\right)$, where $R_{1}$ and $R_{2}$ are the principal radii of curvature of the interface. For spherical droplets $R_{1}=R_{2}=R$. For menisci, we designate $R_{1}$ as positive and $R_{2}$ as negative. Thus:

$$
\Delta P_{L a p}=\gamma\left(\frac{1}{R_{1}}+\frac{1}{R_{2}}\right)
$$

In the concave shape of a meniscus, one of the radii of curvature $\left(R_{2}\right)$ is negative (Figure 3 (A)Error! Reference source not found.). Thus, when the magnitude of $R_{l}$ is greater than the 
magnitude of $R_{2}$, the Laplace pressure will also be negative. Such negative pressures have been measured for nano-scale menisci formed by capillary condensation between an AFM tip and substrate, with the magnitude of the pressure being up to $140 \mathrm{MPa} .{ }^{41}$

In Figure 3 we consider a liquid meniscus of micron scale where the sharpness of the tip is negligible. Due to the inclination angle of the tip pyramid $\left(\alpha_{t i p} \sim 45^{\circ}\right), R_{1} \sim R_{2}$ and the Laplace pressure in the meniscus is approximately zero $\left(\Delta P_{m} \sim 0\right)$. The Laplace pressure in the ink at the base of the tip is positive $\left(\Delta P_{t i p}>0\right)$, a situation maintained because the base of the pyramid meets the cantilever at $135^{\circ}$, causing $R_{1}<R_{2}$. Thus, when an AFM tip touches the substrate, a pressure gradient is set up from the top to the bottom of the tip according to the difference in Laplace pressure. According to Pascal's law the liquid must flow from the higher to the lower pressure region. $^{42}$

If the Laplace pressure in the tip reservoir $\left(\Delta P_{t i p}\right)$ is proportional to the volume of ink, then this driving pressure will decrease during an experiment as ink is depleted. Although we have not done so in this work, one method to quantify the Laplace pressure for a given volume in this geometry may be to use a simulation method based on energy minimization, such as the Surface Evolver software. ${ }^{43}$ In this analysis, tip geometry is a crucial factor. Deposition should be more difficult to achieve with high aspect ratio tips, and easier to achieve with lower aspect ratio tips. An investigation of how deposition rate depends on the inclination angle, $\alpha_{t i p}$, could shed light on the degree to which Laplace pressure is driving deposition.

The apparent increase in viscosity in cases of nanoscale confinement may also affect deposition, especially as the thickness of flow, along the tip and in the spreading meniscus, may concerns films of $<10 \mathrm{~nm}$ thickness. ${ }^{47}$ The retraction rate of the tip is likely also an important parameter. Though we have only used one retract rate in this work, a study which systematically 
varied retract rate and deposition volume could elucidate important information regarding the dynamics of deposition and the morphology of resulting droplets.

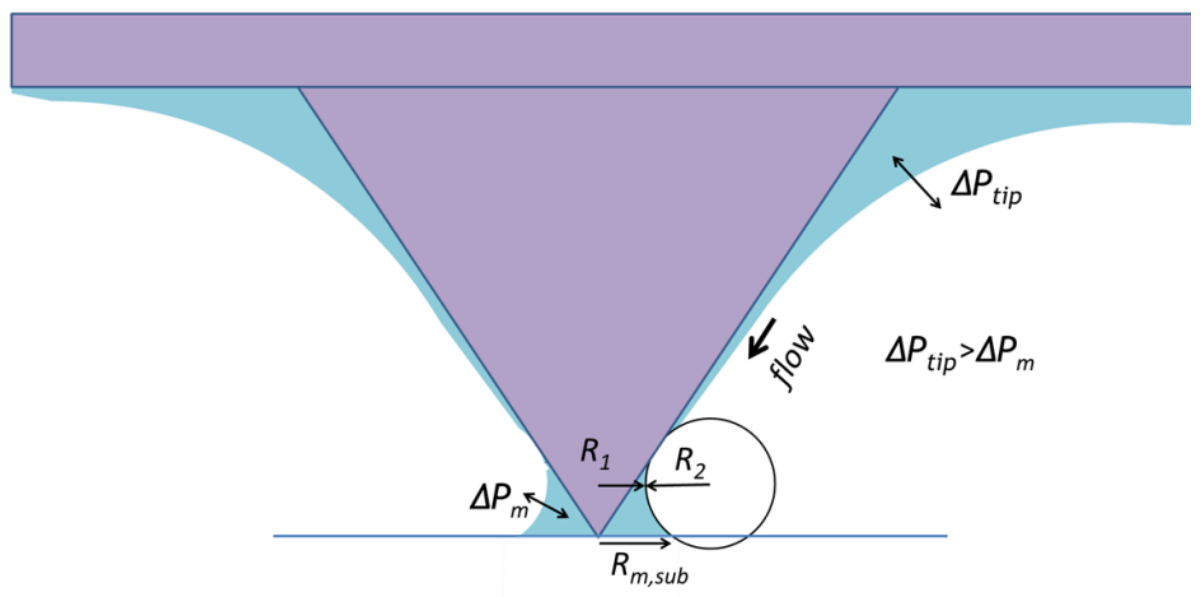

Figure 3: The dependence of deposition rate on volume of ink on the pen. (A) Illustration of the Laplace pressure gradient as the suggested driving force for liquid ink deposition.

In molecular ink DPN, the driving force and many intrinsic factors were elucidated before the effect of tip coating levels and ink depletion effects became apparent. ${ }^{37,38}$ On the contrary, we have found that 'ink loading' is the dominant factor affecting deposition rate for AFM deposition of liquids. Changes in ink loading can result in a tenfold decrease in deposition rate over two hours printing time. The volume dependence was so strong that no inherent effects resulting from the differences in ink properties (i.e. differing viscosity) or substrate wettability could be identified from our data. We conclude that the understanding of liquid ink deposition must begin with an understanding of the effect of changing ink volume on the tip. Our work has continued in that direction, with a manuscript detailing these results to be published separately. ${ }^{44}$ 
As deposition rate changes significantly during a print run, the empirical control of dwell time may not be the most useful means to control feature size. There arises a need to monitor, in situ, the size of each deposited feature. This will be further examined in the next section.

\subsection{Deposition monitoring using AFM force curves}

AFM force measurements have been used for two decades to model the formation of liquid meniscii at nanoscale apertures. ${ }^{34}$ For example, the adhesion force between a tip and substrate can be used to monitor the capillary condensation of a water meniscus at various relative humidities. ${ }^{45}$ More recently, AFM force measurements have been used to gain insight into the mechanism of liquid deposition from a nano-fountain pen. ${ }^{27}$ Besides the direct information acquired about the underlying ink-transfer mechanism, the force curves being generated may allow for a direct method to monitor feature size in-situ and in real time (without timeconsuming AFM imaging). Such a capability, besides being useful and time-saving in an inkdevelopment project, would also prove invaluable during a potential device manufacture; it would provide a means to instantaneous error detection (and correction).

The ink-transfer mechanism was probed by monitoring the forces experienced by the AFM tip during deposition of the NOA68T (25000 mPa.s) model ink on hydrophilic Si/SiOx substrates. Grids of dots were deposited (Figure 4A) and the deflection of the cantilever was measured and used to generate a force curve. The z-height has been adjusted to account for the bending of the cantilever (i.e. sensitivity) and so the curves are plotted as force versus 'tip-sample separation'. After AFM imaging of the printed pattern, analysis of individual force curves could proceed with respect to the dimensions of the specific dot deposited. For example, Figure 4 (B) shows a force 
map compiled by plotting the maximum adhesion force against the coordinates of each dot imaged in (A).

The data of interest is within the force retraction curve, generated when the tip is being withdrawn from the surface. Each retract curve exhibits three stages (Figure 4C). In stage 1, the tip maintains contact with the surface as it is pinned down by the capillary force of ink on the substrate. When the cantilever restoring force exceeds the pinning force of the meniscus, the tip pulls away and draws a thin 'capillary bridge' of ink between itself and the substrate (stage 2). The capillary bridge "necks" (becomes thinner) as it is drawn, and hence the force on the tip decreases. When the neck of the capillary bridge breaks, the force returns to zero, and this indicates the completion of the deposition event. In the third stage of the retract curve, the tip completes its retraction at zero deflection, with zero force on the tip. Detailed discussions of the changing adhesion force profile during retraction have been provided by both Chaudhury and Ondarçuhu. ${ }^{27,32}$ 

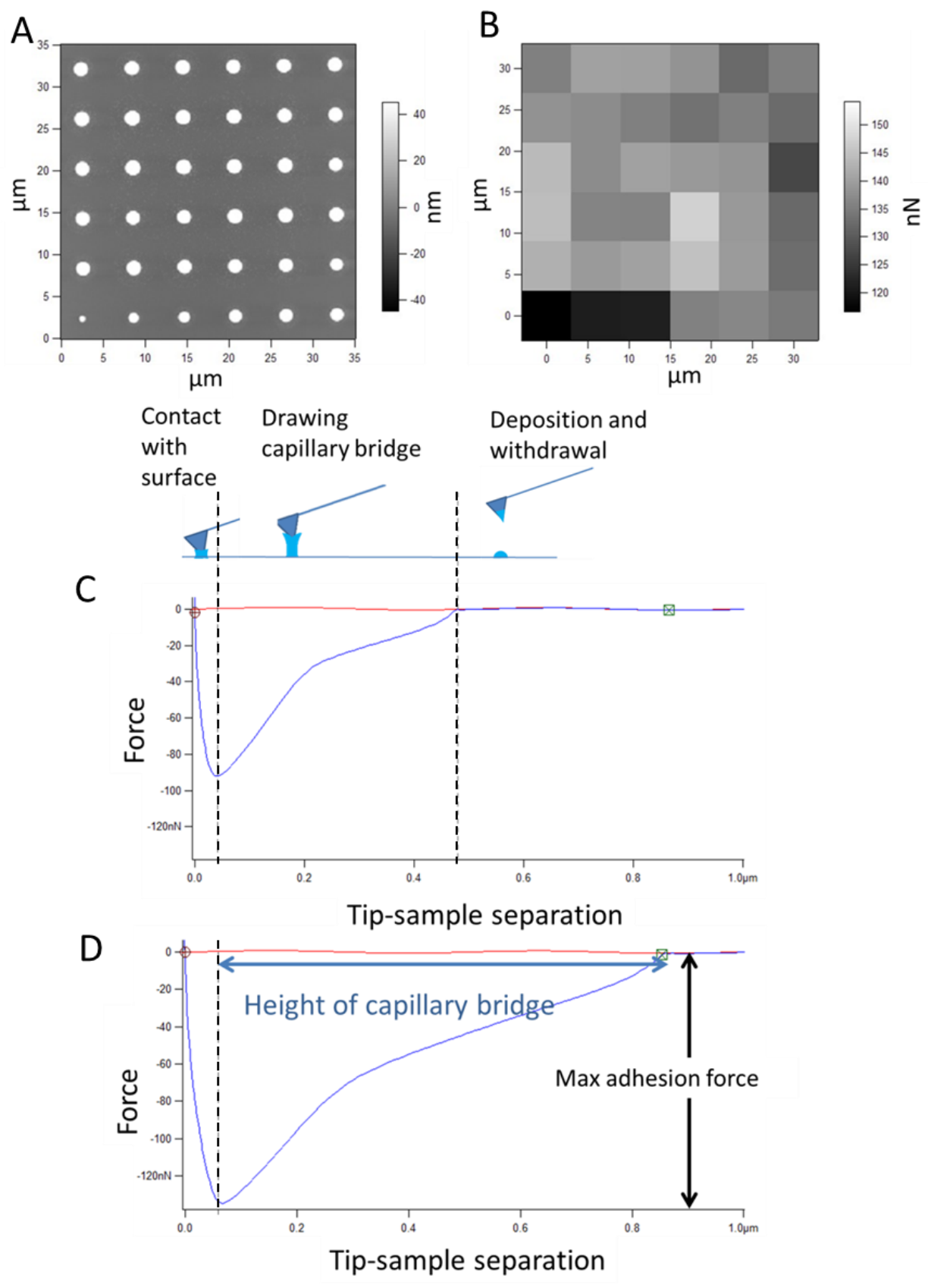

Figure 4. Force monitoring data: (A) AFM topography image of a 6x6 array of NOA68T dots (5s dwell time) on hydrophilic $\mathrm{Si} / \mathrm{SiOx}$; (B) Force map generated from the maximum adhesion force (retraction curve) registered during the deposition of each dot; (C) The force curve (retraction) recorded during deposition of the bottom-left dot in the grid (radius $450 \mathrm{~nm}$ ). Three sections of the retract curve are labeled; contact with surface, 
drawing of the capillary bridge, and final deposition; (D) The force curve (retraction) recorded during the deposition of bottom right dot in the grid (radius $780 \mathrm{~nm}$ ). The cantilever experiences larger forces and greater capillary bridge extension when larger dots are deposited.

To achieve reliable deposition monitoring, a direct relationship must be demonstrated between some feature of the force curve and resulting dot dimensions. Figure 4 (C) and (D) show force curves for two separate deposited dots; one of radius $450 \mathrm{~nm}$ and one of radius $780 \mathrm{~nm}$. It is clear that the force curve corresponding to the larger dot has a very different profile, with a stronger maximum adhesion force force (130 $\mathrm{nN}$ as opposed to $90 \mathrm{nN})$, a greater total adhesion energy (40.43 fJ as opposed to $18.85 \mathrm{fJ}$ ), and a greater height of the capillary bridge (477 $\mathrm{nm}$ as opposed to $270 \mathrm{~nm}$ ). In general, deposition of a larger dot generates a larger force on the tip, a higher adhesion energy and an increased height of the capillary bridge at break-point.

Though the maximum adhesion force exhibits a correlation with dot radius (see supporting information), it is not an ideal parameter with which to monitor deposition. The adhesion force arises from capillary, $F_{C a p}$, and Laplace, $\underline{F}_{\underline{L a p}}$, forces which depend on the geometry of the tipink-substrate meniscus. As shown in Figure 5 (A), this geometry is complex, involving parameters such as the radius of ink contact around the tip, $R_{m, t i p}$, the meniscus radius at the substrate $\left(R_{m, s u b}\right)$, the meniscus height on the tip $\left(h_{m, t i p}\right)$, the ink-substrate contact angle $\left(\theta_{a d v}\right)$, and the ink-tip contact angle $\left(\theta_{\text {tip }}\right)$. All of these parameters are difficult to independently verify, and many of them can change during the retract event. ${ }^{27,32}$

As shown in Figure 5 (B) the meniscus at the instant of break presents a much simplified geometry. If we assume that only the bottom half of the meniscus bridge is deposited on the surface, then no knowledge of the ink-tip interaction geometry is required. To calculate the 
volume of the half-meniscus, we first approximate the meniscus curvature to be semi-circular (a common assumption). ${ }^{46} \mathrm{We}$ also assume the receding contact angle, $\theta_{\text {rec }}$, is near zero (likely for low contact angle systems; $\theta_{c} \sim 7^{\circ}$ for this system). In this case, the height of the meniscus at break, $h_{m}$, is equal to the radius of contact with the substrate, $R_{m, s u b}$ at that instant. By rotational geometry the volume of the meniscus, $V_{m}$, is given by:

$$
V_{m}=\frac{\pi h_{m}^{3}}{6}(10-3 \pi)
$$

If we assume that $V_{m}$ also constitutes the volume of the deposited dot, $V_{d o t}$, then the height of the meniscus bridge may, by itself, be used to calculate the size of the deposited feature.

To investigate this, dots of the NOA68T ink were deposited on hydrophilic $\mathrm{Si} / \mathrm{SiO}_{2}$ using a range of dwell times. The dot volumes ranged from $20 \mathrm{aL}$ to $240 \mathrm{aL}$ and force curves were recorded during each deposition event. The deposited features were subsequently imaged at high resolution using AFM. The dimensions of each dot were then analysed in terms of the force curve of its deposition event.

As shown in Figure $5(\mathrm{C})$, we have found a direct relationship between the height of the meniscus bridge at break, $h_{m}$, (obtained from the force curve) and the radius of deposited dots. Furthermore, as shown in Figure 5 (D), the volumes of deposited dots (from AFM topographical images) are in excellent agreement with the volumes calculated from meniscus height according to equation $3\left(\mathrm{R}^{2}=0.9899\right)$, supporting our assumption that $V_{m}=V_{\text {dot }}$. Such a level of agreement is promising for an in-situ, real time, deposition monitoring system. 
A

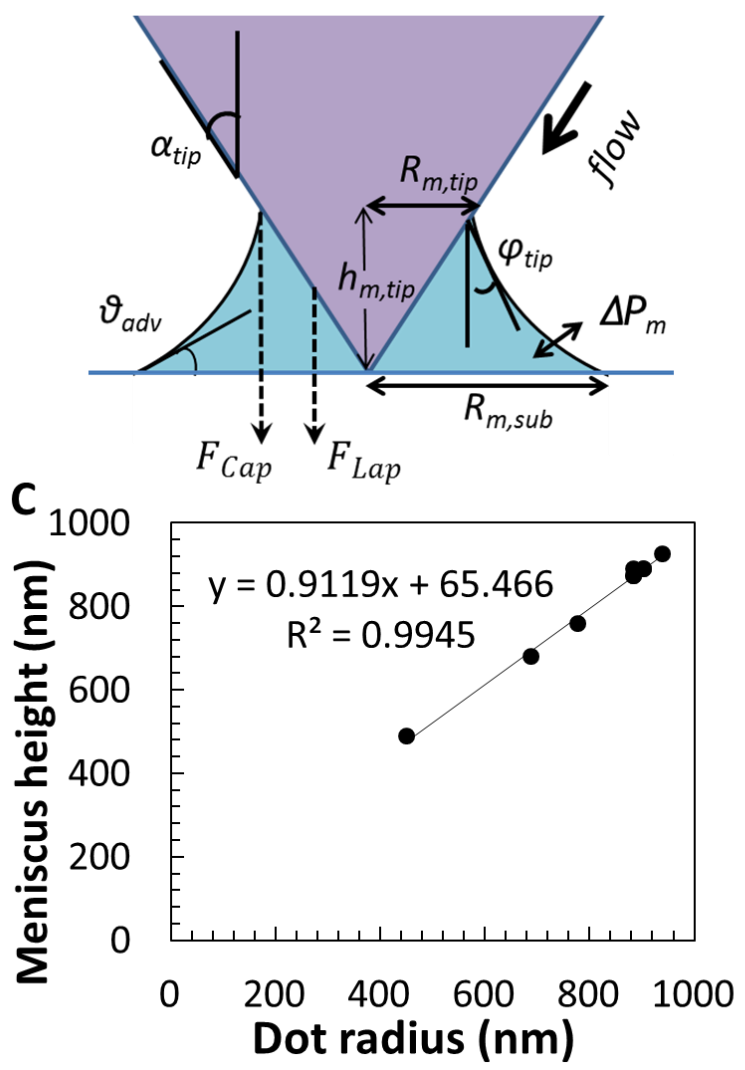

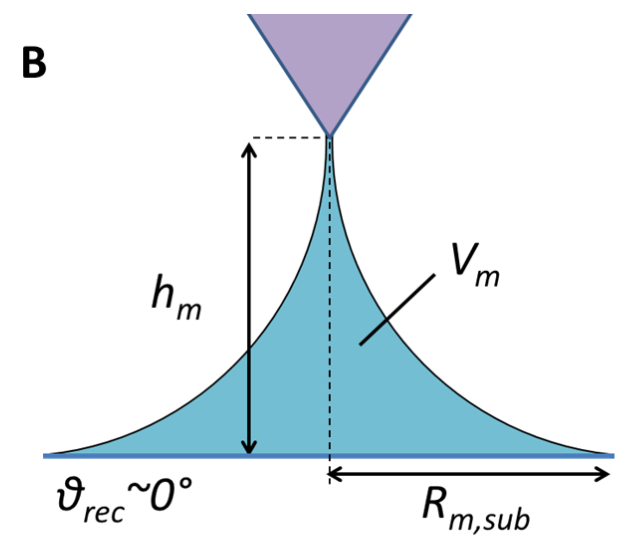

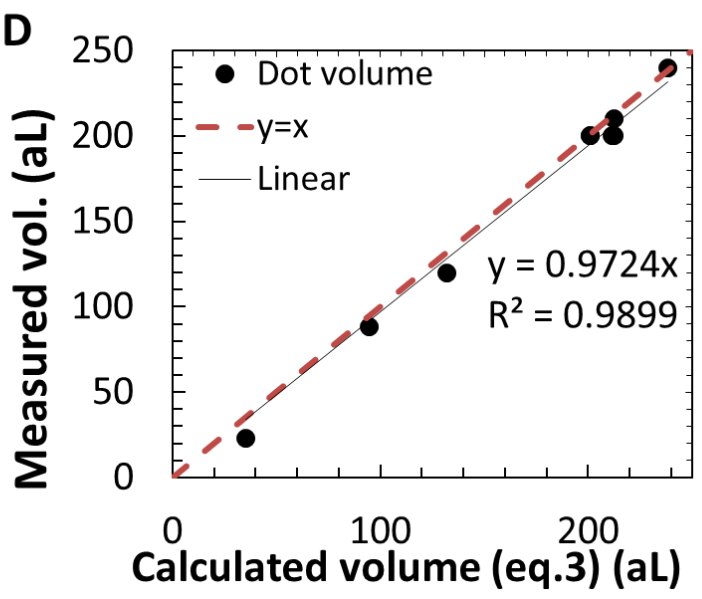

Figure 5. Obtaining deposited dot volume from the deposition force curve. (A) The adhesion force originates from the capillary and Laplace forces defined by the geometry of the meniscus between tip and substrate. (B) At its break point, the meniscus attains a simplified geometry. If the receding contact angle is $\sim 0^{\circ}$, then the height of the meniscus, $h_{m}$, is equal to the radius of contact with the substrate, $\boldsymbol{R}_{m, s u b}$. Using simple geometry, the volume of the meniscus can be calculated using the meniscus height parameter only. (C) The height of the meniscus bridge (i.e. force curve 'extension length') exhibits a strong direct relationship $\left(\mathrm{R}^{2}=0.99\right)$ with dot radius. (D) The volume of deposited dots (as measured by AFM) plotted against the volume calculated from meniscus height according to equation 3. The measured and calculated volumes are in very good agreement, showing 
that our assumptions are validated. The linear trendline and line of perfect correlation, $y=x$, are plotted for comparison.

\subsection{Different mechanisms for molecular ink DPN and liquid ink deposition}

Throughout this paper, we have described several phenomena which have not been observed for DPN of molecular inks. The deposition dynamics were found to vary for different inksubstrate systems. The deposition rate was found to decrease dramatically as the volume of ink in the cantilever reservoir was depleted. Deposition was found to occur, not via diffusion, but via the breaking of a meniscus bridge between tip and substrate. Since 'DPN' nominally refers to diffusive transport from an AFM tip, we suggest that a distinction should be drawn between molecular ink DPN and the deposition of liquids from an AFM tip.

Figure 6 illustrates the differing ink transport mechanisms for molecular ink DPN and liquid ink deposition. DPN of molecular inks involves five distinct stages: (1) Pre-treatment of tip and substrate; (2) Coating the AFM tip with dried ink (typically alkanethiol molecules); (3) Contact of the tip with the surface and the formation of a water meniscus between the tip and substrate due to capillary condensation; (4) Diffusion of the ink molecules from tip to substrate. The diffusion may or may not be facilitated by dissolution in the water meniscus, depending on the hydrophilicity of the molecule; (5) Lateral diffusion of the molecules on the substrate and covalent attachment.

In DPN of liquid inks, the deposition mechanism is very different: (1) Pre-treatment of tip and substrate; (2) The DPN tip is inked by dipping it into a microfluidic inkwell, after which the ink is held in a reservoir etched into the underside of the cantilever; (3) When the tip is brought into contact with substrate, liquid ink 'flows' down to form a meniscus between tip and sample. The 
volume of this meniscus grows with increasing dwell time; (4) When the tip retracts it distends a meniscus bridge between tip and substrate. (5) The meniscus bridge breaks and the deposited droplet forms a spherical cap on the substrate.

DPN of molecular inks

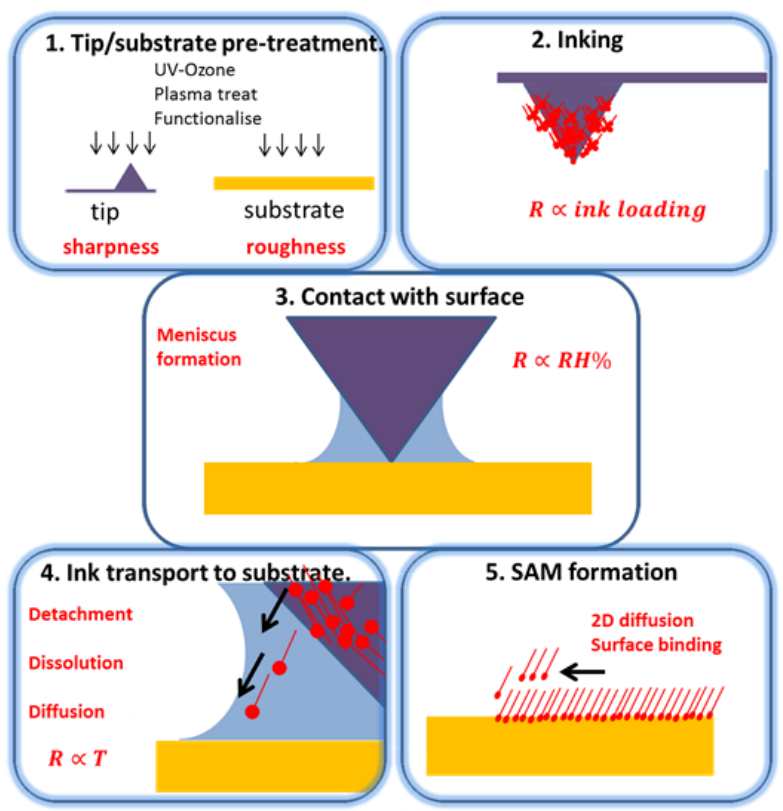

Deposition of liquid from an AFM tip

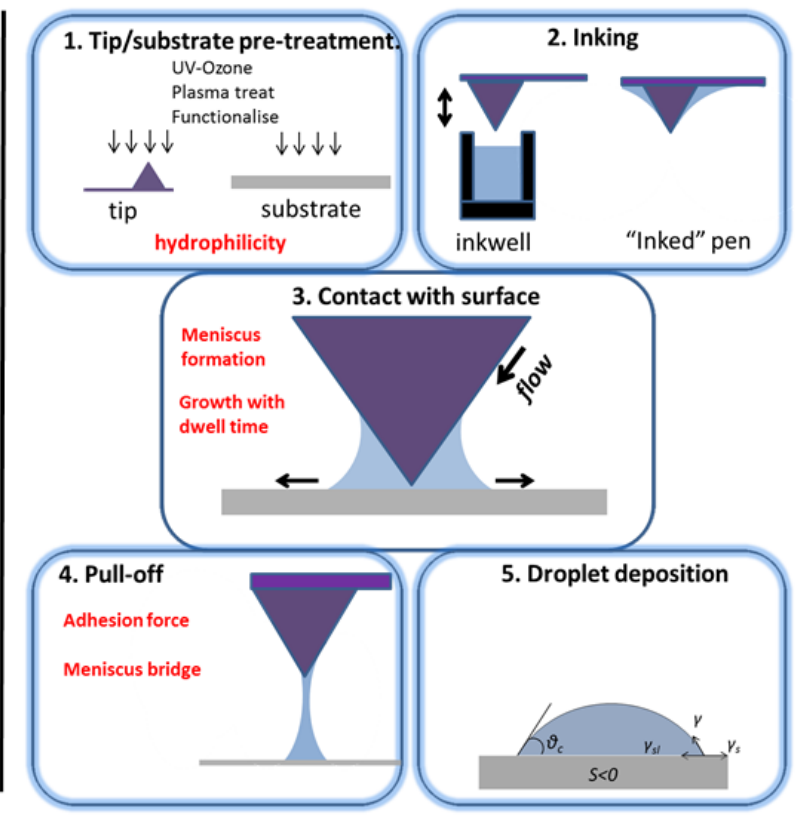

Figure 6: Illustrations of the differing mechanisms of ink deposition in DPN of molecular inks and AFM deposition of liquids. Molecular ink transport involves diffusion from tip to substrate, often facilitated by a condensed water meniscus. Some of the key parameters affecting transport rate, $R$, are highlighted. Liquid ink deposition involves flow into an ink meniscus between tip and substrate. When the tip is retracted, the ink is distended into a meniscus bridge. Droplet deposition occurs upon breaking of the meniscus bridge.

DPN of molecular inks and deposition of liquid from an AFM tip may not be mutually exclusive. For example, several molecular ink DPN studies have used liquid components to facilitate diffusive transport. $^{48,49}$ (The liquids in these studies, such as ethanol, dimethyl formamide or dimethyl sulfoxide, are usually volatile and do not remain constituents of the 
functional pattern.) Conversely, some diffusive transport may occur as a component of liquid ink transport. (Though we have not explored the parameter in this study, relative humidity does affect the deposition rate of the NOA inks). Ultimately, as features of smaller dimensions are considered, a distinction between 'liquid ink' and 'molecular ink' may not be valid. Nevertheless, a distinction between diffusive molecular ink transport versus deposition via the breaking of a meniscus bridge is useful in many cases as each mechanism highlights different parameters which need to be controlled.

\section{CONCLUSIONS}

A set of model ink-substrate systems were used to develop an understanding of the deposition of liquids by AFM. We began by investigating the growth of dot-size with increasing dwell-time. The dramatic change in deposition rate over the course of an experiment limited our ability to quantify the deposition dynamics in terms of liquid properties and substrate wettability. We found that a critical parameter affecting deposition rate was the volume of ink on the pen.

We analyzed the forces acting upon the AFM cantilever during ink deposition to gain insight into the dynamics of ink-transfer. The force curve data and simple geometrical arguments were used to elucidate the shape of the ink meniscus at the instant of deposition, a methodology which may lead to an accurate and real-time means of monitoring the volume of deposited dots. Such in-situ monitoring could be an important capability for future autonomous fabrication systems. For example, an algorithm could be incorporated using dynamic information from force curves to adapt to specific deposition conditions (level of ink on pen, humidity, local substrate hydrophilicity etc). Ideally, such a system would utilise optical feedback, and individual actuation, on every pen in an array. Although this would necessitate a vastly more complex instrumentation, feedback systems for 2 dimensional arrays of cantilevers were demonstrated 
over a decade ago. ${ }^{50}$ We encountered limitations to the deposition monitoring technique due to the relatively low stiffness $(\mathrm{k} \sim 0.5 \mathrm{~N} / \mathrm{m})$ of the M-type probes. For example, the large adhesion forces generated during deposition of very large dots resulted in bending of the cantilever beyond the limit of detection. This put an upper limit on the magnitude of adhesion forces which could be measured. On the other hand, the meniscus bridge height of very small dots could not be measured as this information was washed out by the cantilever restoring force. Higher sensitivity of detection (and greater control of overcoming the pinning meniscus force) could be achieved with the use of higher stiffness cantilevers.

Taken together, our results illustrate how liquid deposition involves a very different transfer mechanism than traditionally ascribed to molecular transport. Different parameters, in particular the volume of ink on the cantilever, are important in defining deposition rate. In recent work, we have shown that deposition rate depends not just on the volume of ink on the cantilever, but on the relative location of the ink on the cantilever (and on the tip itself) and that this ink distribution is subject to dynamic reorganisation. ${ }^{44}$ The resulting feature-size variation emphasizes the utility of an in-situ deposition monitoring strategy.

\section{ASSOCIATED CONTENT}

Supporting Information. A discussion of the relationship between adhesion force and feature size. This material is available free of charge via the Internet at http://pubs.acs.org.

\section{AUTHOR INFORMATION}

\section{Corresponding Author}

* E-mail: gwallace@uow.edu.au 


\section{Author Contributions}

C.D.O'C and M.J.H. designed experiments. C.D.O'C and D.M. performed experiments. C.D.O'C, M.J.H. and S.E.M. analysed results. C.D.O'C wrote the manuscript. M.J.H and G.G.W. directed the project. All authors have given approval to the final version of the manuscript.

\section{Notes}

The authors declare no competing financial interest.

\section{ACKNOWLEDGMENT}

The authors are grateful for the continued financial support of the Australian Research Council under the Australian Federation and Laureate Fellowships of Prof Gordon Wallace, the Australian Research Fellowship of Assoc. Prof. Michael Higgins and the QEII Fellowship of Assoc. Prof. Simon Moulton. The Nanoink system is gratefully provided via the Australian National Fabrication Facility (ANFF), Materials Node.

\section{REFERENCES}

(1) Piner, R. D. “Dip-Pen” Nanolithography. Science (80-. ). 1999, 283, 661-663.

(2) Sheehan, P.; Whitman, L. Thiol Diffusion and the Role of Humidity in "Dip Pen Nanolithography."Phys. Rev. Lett. 2002, 88, 156104.

(3) Peterson, E. J.; Weeks, B. L.; Yoreo, J. J. De; Schwartz, P. V Effect of Environmental Conditions on Dip Pen Nanolithography of Mercaptohexadecanoic Acid. 2004, 1520615210 .

(4) Giam, L. R.; Wang, Y.; Mirkin, C. A. Nanoscale molecular transport: the case of dip-pen nanolithography. J. Phys. Chem. A 2009, 113, 3779-82. 
(5) Hong, S. Multiple Ink Nanolithography: Toward a Multiple-Pen Nano-Plotter. Science (80-. ). 1999, 286, 523-525.

(6) Rozhok, S.; Piner, R.; Mirkin, C. a. Dip-Pen Nanolithography: What Controls Ink Transport? J. Phys. Chem. B 2003, 107, 751-757.

(7) Wu, C.-D.; Fang, T.-H. Simulation of deposition of ink molecules on rough substrates in dip-pen nanolithography. Model. Simul. Mater. Sci. Eng. 2011, 19, 065008.

(8) Weeks, B.; Noy, A.; Miller, A.; De Yoreo, J. Effect of Dissolution Kinetics on Feature Size in Dip-Pen Nanolithography. Phys. Rev. Lett. 2002, 88, 1-4.

(9) Saha, S. K.; Culpepper, M. L. An Ink Transport Model for Prediction of Feature Size in Dip Pen Nanolithography. Small 2010, 15364-15369.

(10) Ahn, Y.; Hong, S.; Jang, J. Growth dynamics of self-assembled monolayers in dip-pen nanolithography. J. Phys. Chem. B 2006, 110, 4270-3.

(11) Wu, C.-D.; Fang, T.-H.; Lin, J.-F. Formation mechanism and mechanics of dip-pen nanolithography using molecular dynamics. Langmuir 2010, 26, 3237-41.

(12) Chung, S.; Felts, J. R.; Wang, D.; King, W. P.; De Yoreo, J. J. Temperature-dependence of ink transport during thermal dip-pen nanolithography. Appl. Phys. Lett. 2011, 99, 193101.

(13) Wang, H.; Nafday, O. A.; Haaheim, J. R.; Tevaarwerk, E.; Amro, N. A.; Sanedrin, R. G.; Chang, C.; Ren, F.; Pearton, S. J. Toward conductive traces: Dip Pen Nanolithography® of silver nanoparticle-based inks. Appl. Phys. Lett. 2008, 93, 143105.

(14) Hung, S.; Nafday, O. A.; Haaheim, J. R.; Ren, F.; Chi, G. C.; Pearton, S. J. Dip Pen Nanolithography of Conductive Silver Traces. J. Phys. Chem. C 2010, 114, 9672-9677.

(15) Senesi, A. J.; Rozkiewicz, D. I.; Reinhoudt, D. N.; Mirkin, C. A. Agarose-assisted dip-pen nanolithography of oligonucleotides and proteins. ACS Nano 2009, 3, 2394-402.

(16) Sanedrin, R. G.; Huang, L.; Jang, J.-W.; Kakkassery, J.; Mirkin, C. A. Polyethylene Glycol as a Novel Resist and Sacrificial Material for Generating Positive and Negative Nanostructures**. 2008, 920-924.

(17) Nakashima, H.; Higgins, M. J.; O’Connell, C.; Torimitsu, K.; Wallace, G. G. Liquid deposition patterning of conducting polymer ink onto hard and soft flexible substrates via dip-pen nanolithography. Langmuir 2012, 28, 804-11.

(18) Jang, J.-W.; Zheng, Z.; Lee, O.-S.; Shim, W.; Zheng, G.; Schatz, G. C.; Mirkin, C. a Arrays of nanoscale lenses for subwavelength optical lithography. Nano Lett. 2010, 10, 4399-404. 
(19) Hernandez-Santana, A.; Irvine, E.; Faulds, K.; Graham, D. Rapid prototyping of poly(dimethoxysiloxane) dot arrays by dip-pen nanolithography. Chem. Sci. 2011, 2, 211.

(20) O'Connell, C. D.; Higgins, M. J.; Sullivan, R. P.; Jamali, S. S.; Moulton, S. E.; Wallace, G. G. Nanoscale platinum printing on insulating substrates. Nanotechnology 2013.

(21) Collins, J. M.; Lam, R. T. S.; Yang, Z.; Semsarieh, B.; Smetana, A. B.; Nettikadan, S. Targeted delivery to single cells in precisely controlled microenvironments. Lab Chip 2012, 12, 2643-8.

(22) Nanoink inc. Hydrogel Patterning (Tech note); 2010; pp. 1-2.

(23) Nanoink inc. Patterning Functional Hydrogels (Tech note); 2010; pp. 1-2.

(24) Fang, A.; Dujardin, E.; Ondarçuhu, T. Control of droplet size in liquid nanodispensing. Nano Lett. 2006, 6, 2368-74.

(25) Arcamone, J.; Dujardin, E.; Rius, G.; Pérez-Murano, F.; Ondarçuhu, T. Evaporation of femtoliter sessile droplets monitored with nanomechanical mass sensors. J. Phys. Chem. B 2007, 111, 13020-7.

(26) Ondarçuhu, T.; Arcamone, J.; Fang, a.; Durou, H.; Dujardin, E.; Rius, G.; Pérez-Murano, F. Controlled deposition of nanodroplets on a surface by liquid nanodispensing: Application to the study of the evaporation of femtoliter sessile droplets. Eur. Phys. $J$. Spec. Top. 2009, 166, 15-20.

(27) Fabié, L.; Durou, H.; Ondarçuhu, T. Capillary forces during liquid nanodispensing. Langmuir 2010, 26, 1870-8.

(28) Kim, K.; Moldovan, N.; Espinosa, H. D. Patterning techniques A Nanofountain Probe with Sub-100 nm Molecular Writing Resolution**. 2005, 632-635.

(29) Wu, B.; Ho, A.; Moldovan, N.; Espinosa, H. D. Direct deposition and assembly of gold colloidal particles using a nanofountain probe. Langmuir 2007, 23, 9120-3.

(30) Kim, K.-H.; Sanedrin, R. G.; Ho, A. M.; Lee, S. W.; Moldovan, N.; Mirkin, C. A.; Espinosa, H. D. Direct Delivery and Submicrometer Patterning of DNA by a Nanofountain Probe. Adv. Mater. 2008, 20,330-334.

(31) Loh, O.; Lam, R.; Chen, M.; Moldovan, N.; Huang, H.; Ho, D.; Espinosa, H. D. Nanofountain-probe-based high-resolution patterning and single-cell injection of functionalized nanodiamonds. Small 2009, 5, 1667-74.

(32) Malotky, D. L.; Chaudhury, M. K. Investigation of Capillary Forces Using Atomic Force Microscopy. Langmuir 2001, 17, 7823-7829. 
(33) Men, Y.; Zhang, X.; Wang, W. Capillary liquid bridges in atomic force microscopy: formation, rupture, and hysteresis. J. Chem. Phys. 2009, 131, 184702.

(34) Bhushan, B.; Israelachvili, J. N.; Landman, U. Nanotribology: friction, wear and lubrication at the atomic scale. Nature 1995, 374, 607-616.

(35) Chilamakuri, S. K.; Bhushan, B. A comprehensive kinetic meniscus model for prediction of long-term static friction. J. Appl. Phys. 1999, 86, 4649.

(36) O’Connell, C. D.; Higgins, M. J.; Nakashima, H.; Moulton, S. E.; Wallace, G. G. Vapor phase polymerization of EDOT from submicrometer scale oxidant patterned by dip-pen nanolithography. Langmuir 2012, 28, 9953-60.

(37) Hampton, J. R.; Dameron, A. A.; Weiss, P. S. Transport rates vary with deposition time in dip-pen nanolithography. J. Phys. Chem. B 2005, 109, 23118-20.

(38) Wu, T.-H.; Lu, H.-H.; Lin, C.-W. Dependence of transport rate on area of lithography and pretreatment of tip in dip-pen nanolithography. Langmuir 2012, 28, 14509-13.

(39) Eijkel, J. C. T.; van den Berg, A. Young 4ever--the use of capillarity for passive flow handling in lab on a chip devices. Lab Chip 2006, 6, 1405-8.

(40) Van Honschoten, J. W.; Brunets, N.; Tas, N. R. Capillarity at the nanoscale. Chem. Soc. Rev. 2010, 39, 1096-114.

(41) Yang, S. H.; Nosonovsky, M.; Zhang, H.; Chung, K.-H. Nanoscale water capillary bridges under deeply negative pressure. Chem. Phys. Lett. 2008, 451, 88-92.

(42) Gao, C.; Bhushan, B. Tribological performance of magnetic thin-film glass disks: its relation to surface roughness and lubricant structure and its thickness. Wear 1995, 190, $60-75$.

(43) Brakke, K. a. The Surface Evolver and the Stability of Liquid Surfaces. Philos. Trans. R. Soc. A Math. Phys. Eng. Sci. 1996, 354, 2143-2157.

(44) O’Connell, C. D.; Sullivan, R.; Higgins, M. J.; Moulton, S. E.; Wallace, G. G. Ink-onprobe hydrodynamics in atomic force microscope deposition of liquid inks. Submitted 2013.

(45) Butt, H.-J.; Kappl, M. Normal capillary forces. Adv. Colloid Interface Sci. 2009, 146, 4860 .

(46) Cai, S.; Bhushan, B. Meniscus and viscous forces during normal separation of liquidmediated contacts. Nanotechnology 2007, 18, 465704. 
(47) Ortiz-Young, D.; Chiu, H.-C.; Kim, S.; Voïtchovsky, K.; Riedo, E. The interplay between apparent viscosity and wettability in nanoconfined water. Nat. Commun. 2013, 4, 2482.

(48) Demers, L. M.; Ginger, D. S.; Park, S.-J.; Li, Z.; Chung, S.-W.; Mirkin, C. A. Direct patterning of modified oligonucleotides on metals and insulators by dip-pen nanolithography. Science 2002, 296, 1836-8.

(49) Lee, K.-B.; Park, S.-J.; Mirkin, C. a; Smith, J. C.; Mrksich, M. Protein nanoarrays generated by dip-pen nanolithography. Science 2002, 295, 1702-5.

(50) Minne, S. C.; Adams, J. D.; Yaralioglu, G.; Manalis, S. R.; Atalar, A.; Quate, C. F. Centimeter scale atomic force microscope imaging and lithography. Appl. Phys. Lett. 1998, 73, 1742 . 
TOC GRAPHIC

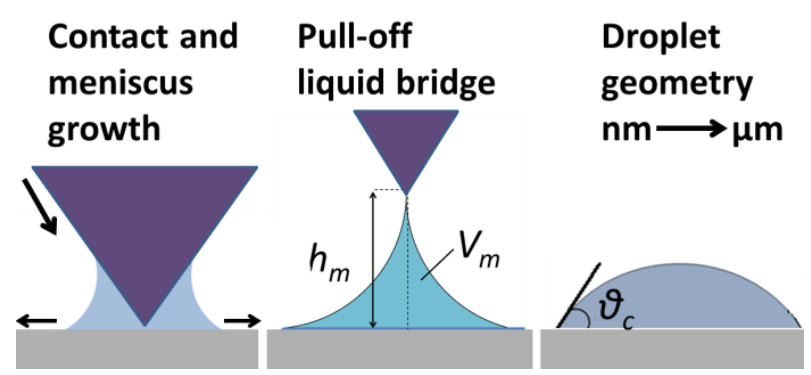

